\title{
Low cost and easy rice husk modification to efficiently enhance ammonium and nitrate adsorption
}

\author{
Lada Mathurasa $^{1} \cdot$ Seelawut Damrongsiri ${ }^{2}$
}

Received: 13 August 2017 / Accepted: 29 January 2018 / Published online: 2 February 2018

(c) The Author(s) 2018. This article is an open access publication

\begin{abstract}
Purpose This research aimed to study the adsorption of ammonium and nitrate by simply modifying the surface of the rice husk using slow pyrolysis and surfactants modification.

Methods Rice husk biochar was prepared by slowly pyrolyzing at $500{ }^{\circ} \mathrm{C}, 2 \mathrm{~h}$. The rice husk and its biochar were modified by cetyltrimethylammonium bromide or sodium dodecylbenzenesulfonate. FTIR, BET and zeta potential measurements were used to characterize the obtained adsorbents.

Results Slow pyrolysis increased the specific surface area and decreased the surface charge of rice husk while surfactant clogged the pore but could change the charge of a surface. Adsorption of both ammonium and nitrate on rice husk, its biochar, and their modification with surfactants fitted Freundlich and Langmuir isotherms, indicating heterogeneity in adsorption. Slow pyrolysis gave the highest ammonium removal with maximum adsorption capacity of $44 \mathrm{mgN} / \mathrm{g}$ and it was a physical process. The cetyltrimethylammonium bromide modification gave a significant nitrate removal on both rice husk and its biochar with maximum adsorption of 278 and $213 \mathrm{mgN} / \mathrm{g}$, respectively, which is higher than a commercial adsorbent.

Conclusions These two modification techniques gave great adsorption enhancement with cost-effectiveness as compared to other reviewed methods which could use as a nitrogen-rich fertilizer and fertilizer retainment in crop production.
\end{abstract}

Keywords Ammonium $\cdot$ Nitrate $\cdot$ Rice husk $\cdot$ Pyrolysis $\cdot$ Surfactant

\section{Introduction}

Nitrogen contamination of water bodies is a worsening global problem causing eutrophication of water which is toxic to aquatic life. Ammonium and nitrate are major causes of the problem, especially from the agricultural sector. There are many techniques used to remove nitrogen including adsorption. Rice husk, one of the major agricultural wastes, is a more cost-effective adsorbent compared to commercial adsorbents. It also enhances growth of the plants (Mustafa et al. 2016). Natural materials, however, may not adsorb a

Lada Mathurasa

lada@pnru.ac.th

Seelawut Damrongsiri

sdamrongsiri@gmail.com

1 Department of Environmental Science, Faculty of Science and Technology, Phranakhon Rajabhat University, Bangkok, Thailand

2 Environmental Research Institute, Chulalongkorn University, Bangkok, Thailand certain pollutant efficiently. Accordingly, surface modification normally is applied to increase the adsorption efficiency and capacity of the biomass. There have been several studies on improvement of biomass adsorption of nitrogen as with pyrolysis (Zeng et al. 2013), $\mathrm{NaOH}$ pre-treatment (Liu et al. 2016), carboxylic acid modification (Halim et al. 2013), acid treatment (Gai et al. 2014), and cross linking with epichlorohydrin (Wang et al. 2007).

From the various techniques used, pyrolysis is especially interesting since it is simple, practical, and is a well-known technique. Zeng et al. (2013) showed that the adsorption of ammonium on pyrolyzed phytoremediation plants could be varied depending on pyrolysis temperature. Kizito et al. (2015) indicated that around 60\% of ammonium from piggery manure could be removed by rice husk and wood biochar. Biochar also offers a mechanism for developing slow release fertilizers (Hou et al. 2016). Another attractive technique is surfactant modification since it can provide positive and negative charges to the modified surface. Mathurasa and Damrongsiri (2017) showed that surfactant could be adsorbed onto rice husk 
and rice husk biochar through Van der Waals force and had a potential to increase the adsorption of ammonium and nitrate. In addition, many surfactants are common, readily available household chemicals; so the know-how and techniques are readily transferred to the farmer. There are some further studies which attempt to modify clay minerals with cationic surfactants to improve nitrate adsorption (Aroke et al. 2014; Ozcan et al. 2005).

Combining surfactant modification and pyrolysis of biomass is a new approach which may enhance the adsorption of nitrogen. The focus of this research is, therefore, to investigate the adsorption of ammonium and nitrate using rice husk and its biochar following surface modification using positive- and negative-charged surfactants.

\section{Materials and methods}

\section{Materials/chemicals}

Rice husk was purchased from a mill in Nonthaburi Province, Thailand. Two low cost and biodegradable surfactants were used. Cetyltrimethylammonium bromide (CTAB), a positive-charge surfactant, and sodium dodecylbenzenesulfonate (SDBS), a negative-charge surfactant, were purchased from Fluka and Aldrich, respectively. $\mathrm{KNO}_{3}(\geq 99 \%)$ and $\left(\mathrm{NH}_{4}\right)_{2} \mathrm{SO}_{4}(\geq 99 \%)$ were purchased from Ajax Finechem.

\section{Adsorbent preparation}

The rice husk was prior cleaned with DI water, and air dried before use. A rice husk adsorbent ( $\mathrm{RH})$ was prepared by grinding and sieving the cleaned rice husk to the size of $0.600-0.106 \mathrm{~mm}$. A rice husk biochar (RHB) was prepared by slowly pyrolyzing rice husk at $500{ }^{\circ} \mathrm{C}, 2 \mathrm{~h}$, in a furnace and then ground to the same size as $\mathrm{RH}$. The $\mathrm{pH}$ of RH and RHB were $6.5 \pm 0.5$ and $7.8 \pm 0.5$, respectively. The CTAB-modified RH or RHB (C-RH or C-RHB) and SDBS-modified RH or RHB (S-RH or S-RHB) were prepared by soaking $1 \mathrm{~g}$ of solid per $20 \mathrm{ml}$ of $30 \mathrm{mM}$ SDBS or $90 \mathrm{mM}$ CTAB. These surfactant concentrations ensured the saturation of surface (Mathurasa and Damrongsiri 2017). The samples were rinsed 3 times with DI water and then dried at $60{ }^{\circ} \mathrm{C}$ using a standard laboratory oven. The properties of each adsorbent were analyzed as follows: the specific surface area, total pore volume, and average pore diameter using BET technique model Autosorb-1; zeta potential by zetasizer model ZSP; and surface functional by FTIR model Nicolet 6700. All calculation was based on the dry weight of the adsorbent.

\section{Adsorption experiments}

The working solutions of ammonium and nitrate at different concentrations, $30-3000 \mathrm{mgN} / \mathrm{l}$, were prepared from the stock solution of $5000 \mathrm{mgN} / \mathrm{l}$ of $\left(\mathrm{NH}_{4}\right)_{2} \mathrm{SO}_{4}$ and $\mathrm{KNO}_{3}$, respectively. The equilibrium batch adsorption was carried out by shaking $20 \mathrm{ml}$ solution with $2 \mathrm{~g}$ adsorbent in a $50 \mathrm{ml}$ centrifuge tube at $250 \mathrm{rpm}$ for $4 \mathrm{~h}$ at $25 \pm 1{ }^{\circ} \mathrm{C}$, then filtered through Whatman filter paper no. 42 to obtain an aqueous phase. The aqueous phase was determined using a WTW analyzer, model Terminal 740 series, with an ammonia probe for ammonium and nitrate probe for nitrate. The amount of ammonium or nitrate ion adsorbed $\left(q_{\mathrm{e}}\right)$ was calculated using Eq. (1):

$q_{\mathrm{e}}=\frac{\left(C_{\mathrm{i}}-C_{\mathrm{e}}\right) V}{m}$

where $q_{\mathrm{e}}$ is the adsorbed concentration $(\mathrm{mgN} / \mathrm{g}), C_{\mathrm{i}}$ is the initial concentration $(\mathrm{mgN} / \mathrm{l}), C_{\mathrm{e}}$ is the equilibrium concentration $(\mathrm{mgN} / \mathrm{l}), m$ is the mass of adsorbent based on dry weight (g), $V$ is the volume of solution (1). The $q_{\mathrm{e}}$ and $C_{\mathrm{e}}$ were analyzed for the isotherm of Langmuir, Freundlich and Dubinin-Radushkevich and the fitness was observed by its $R$ square. The Langmuir isotherm assumes that adsorbate, ammonium or nitrate ion, is adsorbed homogeneously at a specific site on the surface of adsorbent without interaction between the adsorbed molecules (Langmuir 1916). The linearized Langmuir isotherm is as Eq. (2):

$\frac{C_{\mathrm{e}}}{q_{\mathrm{e}}}=\frac{1}{K_{\mathrm{L}} q_{m}}+\frac{C_{\mathrm{e}}}{q_{m}}$

where $q_{\mathrm{m}}$ is the maximum monolayer coverage capacity ( $\mathrm{mgN} / \mathrm{g}$ ) and $K_{\mathrm{L}}$ is Langmuir isotherm constant $(1 / \mathrm{mgN})$. The Freundlich adsorption can be applied to uneven distribution of adsorption energy on heterogeneous surface or multi-layer adsorption on non-ideal surface as natural biomass (Freundlish 1906). A linearized form of the Freundlich adsorption isotherm is expressed as Eq. (3):

$\log q_{\mathrm{e}}=\log K_{\mathrm{f}}+\frac{1}{n} \log C_{\mathrm{e}}$

where $K_{\mathrm{f}}$ is Freundlich isotherm constant $(\mathrm{mgN} / \mathrm{g})$. The $n$ value indicates heterogeneity of the surface. A value greater than 1 implies favourable conditions for a sorption or chemisorption process and $n$ lower than 1 indicates unfavourable conditions for cooperative adsorption. If the adsorption follows the Langmuir assumption, then $n$ is equal to 1 . The physical and chemical adsorption also tested using the Dubinin-Radushkevich isotherm which is generally applied to express the adsorption mechanism on heterogeneous surfaces (Dubinin and Radushkevich 1947). A linearized form of the Dubinin-Radushkevich isotherm is as Eq. (4): 
$\ln \left(q_{\mathrm{e}}\right)=\ln \left(q_{s}\right)-\left(K_{\mathrm{ad}} \varepsilon^{2}\right)$

where $q_{\mathrm{s}}$ is theoretical isotherm saturation capacity $(\mathrm{mgN} / \mathrm{g})$, $K_{\text {ad }}$ is Dubinin-Radushkevich isotherm constant $\left(\mathrm{mol}^{2} / \mathrm{kJ}^{2}\right)$, and $\varepsilon$ is Polanyi potential, which is expressed as Eq. (5):

$\varepsilon=R T \ln \left(1+\frac{1}{C_{e}}\right)$

where $R$ is universal gas constant $(8.314 \mathrm{~J} / \mathrm{mol} \mathrm{K})$ and $T$ is absolute temperature $(\mathrm{K})$. The constant $K_{\mathrm{ad}}$ in Dubinin-Radushkevich isotherm is indicative of the mean adsorption energy $(E)(\mathrm{kJ} / \mathrm{mol})$ of adsorption per mole of the adsorbate (Mahmoud 2015). It can be calculated as Eq. (6):

$E=\frac{1}{\sqrt{2 K_{\mathrm{ad}}}}$

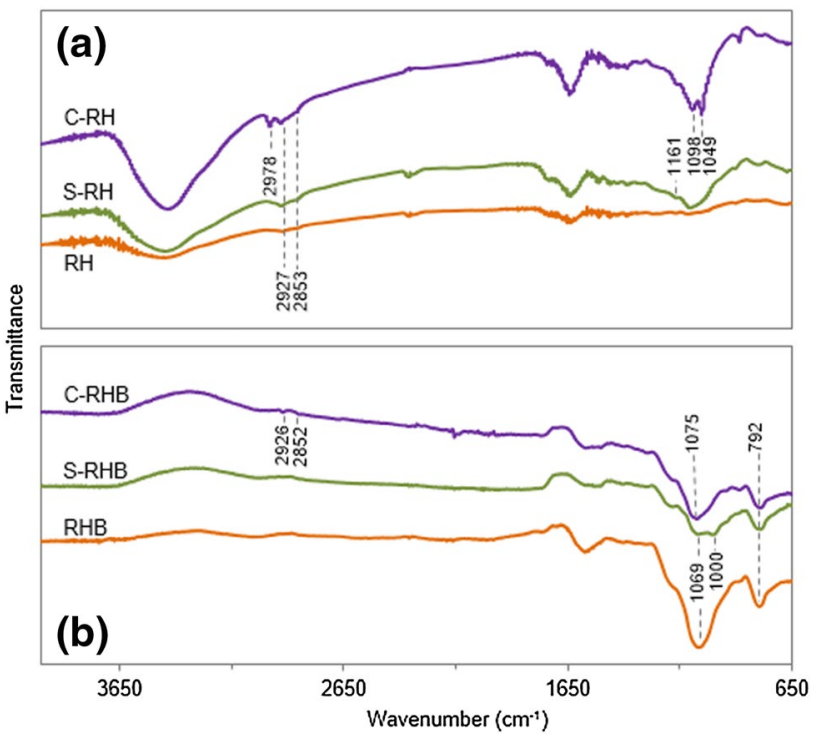

Fig. 1 FTIR spectra of a rice husk (RH) and $\mathbf{b}$ rice husk biochar (RHB) and their modification with CTAB (C-) and SDBS (S-)

\section{Results and discussion}

\section{Properties of adsorbent}

The FTIR results of RH and RHB were different (Fig. 1a, b). The peak between 2852 and $2927 \mathrm{~cm}^{-1}$ of RH corresponds to an aliphatic $\mathrm{C}-\mathrm{H}$ stretching vibration which was not noticeable in RHB indicating the labile aliphatic compounds had decreased in RHB (Abdulrazzaq et al. 2014). Moreover, the peak between $1000-1260 \mathrm{~cm}^{-1}$ and at $792 \mathrm{~cm}^{-1}$ of RHB indicated $\mathrm{Si}-\mathrm{O}$ bonds (Tian et al. 2010) and Si stretching (Lippincott et al. 1958), respectively, showed the increase of silica content in RHB as compared to RH (Alvarez et al. 2014). A broad band at $3250-3500 \mathrm{~cm}^{-1}$ of C-RH (Fig. 1a) corresponds to the $\mathrm{N}-\mathrm{H}$ stretching vibration while the peaks at $2978, \sim 2927$, and $\sim 2853 \mathrm{~cm}^{-1}$ were due to $\mathrm{C}-\mathrm{H}$ stretching of a terminal methyl group, anti-symmetrical stretching, and the symmetrical stretching of the methylene group of the aliphatic surfactant tail, respectively. The peaks at $1250-1020 \mathrm{~cm}^{-1}$ indicate the vibration of the $\mathrm{C}-\mathrm{N}$ bond, confirming the presence of CTAB on C-RH. The results for C-RHB (Fig. 1b) were similar with the characteristic peaks found at 2926, 2852 and $1075 \mathrm{~cm}^{-1}$. These characteristic peaks of CTAB are consistent with the results of Taffarel and Rubio (2010), Quan et al. (2015) and Ramimoghadam et al. (2012). A peak at $1161 \mathrm{~cm}^{-1}$ of S-RH (Fig. 1a) indicates the $\mathrm{S}=\mathrm{O}$ group of sulfonic acid and a peak at $1000 \mathrm{~cm}^{-1}$ of S-RHB (Fig. 1b) indicates the S-O group of sulfonate, signifying the presence of SDBS.

The surfactants binding was also confirmed by specific surface area, total pore volume, average pore diameter and zeta potential value of the adsorbent RHB, S-RHB, and C-RHB as shown in Table 1. Surfaces modified with surfactant showed decreased specific surface area and total pore volume while increasing zeta potential value. The specific surface area of the adsorbent RHB decreased from 174.80 to $3.67 \mathrm{~m}^{2} / \mathrm{g}$ and $105.10 \mathrm{~m}^{2} / \mathrm{g}$ after modification with SDBS (S-RHB) and CTAB (C-RHB), respectively. This is consistent with the results of $\mathrm{Xi}$ et al. (2010) who showed that CTAB decreased the specific surface areas of clay minerals. The total pore volume of $0.176 \mathrm{~cm}^{3} / \mathrm{g}$ of adsorbent RHB
Table 1 Specific surface area, total pore volume, average pore diameter, and zeta potential of each adsorbent

\begin{tabular}{lclcr}
\hline Adsorbent & $\begin{array}{l}\text { Specific surface area } \\
\left(\mathrm{m}^{2} / \mathrm{g}\right)\end{array}$ & $\begin{array}{l}\text { Total pore volume } \\
\left(\mathrm{cm}^{3} / \mathrm{g}\right)\end{array}$ & $\begin{array}{l}\text { Average pore diam- } \\
\text { eter }(\mathrm{A})\end{array}$ & Zeta potential $(\mathrm{mV})$ \\
\hline RH & 7.02 & 0.025 & 15.5 & $0.21 \pm 0.36$ \\
S-RH & 28.71 & 0.061 & 85.0 & $-4.75 \pm 0.91$ \\
C-RH & 2.78 & 0.065 & 938.1 & $1.70 \pm 1.46$ \\
RHB & 174.80 & 0.176 & 40.2 & $-36.57 \pm 2.05$ \\
S-RHB & 3.67 & 0.119 & 1299.0 & $-28.37 \pm 1.50$ \\
C-RHB & 105.10 & 0.098 & 37.2 & $-27.33 \pm 4.37$ \\
\hline
\end{tabular}


reduced to 0.119 and $0.098 \mathrm{~cm}^{3} / \mathrm{g}$ for adsorbent $\mathrm{S}$-RHB and C-RHB, respectively. These decreases in the specific surface area may result from the pore filling by surfactant (Berthod and Garcia-Alvarez-Coque 2000). The pore diameter also changed: the average pore diameter of the S-RHB was greater than of RHB while the average pore size of C-RHB was slightly decreased as compared to RHB. The zeta potential indicating surface charge also increased after modified with surfactants. These changes indicated that CTAB and SDBS surfactant clogged the small pore on the surface of RHB and creating a new surface.

Analysis of the surface of RH as compared to S-RH and $\mathrm{C}-\mathrm{RH}$, found that surfactant broadened the average pore diameter from $15.5 \AA$ to values of $85.0 \AA$ and $938.1 \AA$, respectively (Table 1). A surfactant could either increase or decrease the surface area of rice husk; the specific surface area of S-RH rose from $7.02 \mathrm{~m}^{2} / \mathrm{g}$ of RH to $28.71 \mathrm{~m}^{2} / \mathrm{g}$ while the specific surface area of C-RH was $2.78 \mathrm{~m}^{2} / \mathrm{g}$. These results are consistent with those of Wang et al. (2004) who studied the effect of absorbing surfactants, tetramethylammonium chloride and hexadecyltrimethylammonium bromide, on the pore structure of Ca-montmorillonite. They reported that the cationic surfactant could make the surface area, pore volume, pore size and surface fractal dimension $D$ of the adsorbent greater or lesser depending on the size, the molecular arrangement, and degree of hydration of the exchanged ion in the clay. The zeta potential values of S-RH and $\mathrm{C}-\mathrm{RH}$ were decreased and increased as compared to $\mathrm{RH}$, respectively. These confirmed that surfactants could modify the surface charge of material.

\section{Adsorption of ammonium}

Data of ammonium adsorption on rice husk, rice husk biochar and their modification with SDBS and CTAB surfactants (Fig. 2) could be fitted well with Freundlich and Langmuir isotherm (Table 2). This is in general agreement with many studies using wood and rice husk biochar (Kizito et al. 2015), giant reed biochar (Hou et al. 2016), wheat

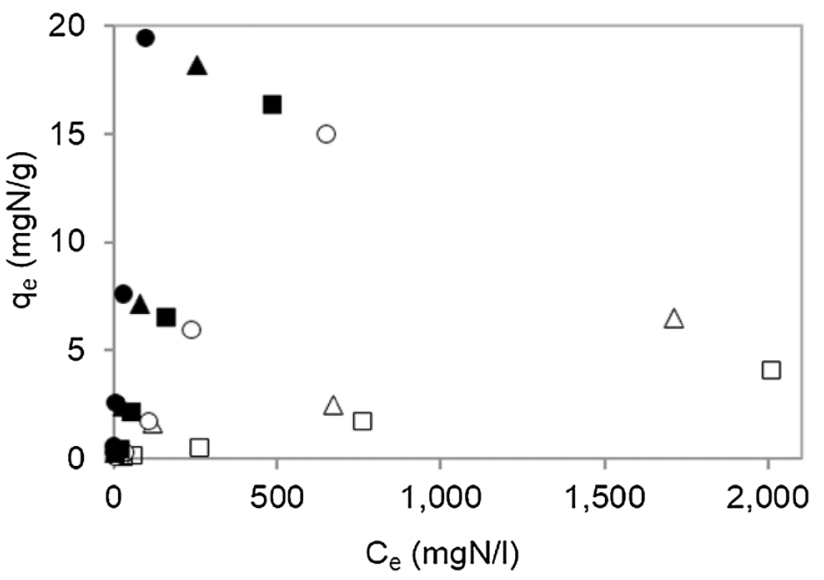

Fig. 2 Adsorption of ammonium 30-3000 mgN/l onto RH (open circle), RHB (filled circle), C-RH (open square), C-RHB (filled square), $\mathrm{S}-\mathrm{RH}$ (open triangle), and S-RHB (filled triangle) at $25 \pm 1^{\circ} \mathrm{C}$, initial $\mathrm{pH}$ of $7.0 \pm 0.5$

straw (Ma et al. 2011), barbecue bamboo charcoal (Zhou et al. 2015), acid-treated zeolite (Dong and Lin 2016), and acid-treated bentonite (Angar et al. 2017) as adsorbents.

The $K_{\mathrm{L}}$ values indicated that RHB was more efficient than RH and the modification with SDBS was more efficient than $\mathrm{CTAB}$, indicating that the surface charge may also play role in the adsorption of ammonium. This is in contrast to the results of Song et al. (2014) who showed that the sediment modified with CTAB had better adsorption of ammonia-nitrogen, nitrate-nitrogen, and phosphorus in seawater as compared to SDS and TX-100. These may due to the effect of salt in seawater. However, RHB is better than S-RHB in terms of both capacity $\left(q_{\mathrm{m}}\right)$ and efficiency $\left(K_{\mathrm{f}}\right)$ as the specific surface area of RHB was higher than of S-RHB and zeta potential values of RHB were more negative than S-RHB. The adsorption capacity $\left(q_{\mathrm{m}}\right)$ showed the following behavior: RHB $>$ S-RHB $\sim$ S-RH $\sim$ RH $>$ C-RH $\mathrm{B}>\mathrm{C}-\mathrm{RH}$ which follows the increase of surface area and the decrease of zeta potential values. This confirms that the surface charge and area affect the adsorption of ammonium.
Table 2 Adsorption isotherm of ammonium 30-3000 mgN/1 onto rice husk, rice husk biochar, and their modification with CTAB and SDBS surfactant at $25 \pm 1^{\circ} \mathrm{C}$, initial $\mathrm{pH}$ of $7.0 \pm 0.5$

\begin{tabular}{llllllll}
\hline Isotherm & Parameter & RH & S-RH & C-RH & RHB & S-RHB & C-RHB \\
\hline Langmuir & $q_{\mathrm{m}}$ & 13.95 & 14.49 & 4.43 & 44.05 & 14.73 & 9.30 \\
& $K_{\mathrm{L}}$ & 0.0008 & 0.0009 & 0.0004 & 0.0046 & 0.0051 & 0.0029 \\
& $R^{2}$ & 0.935 & 0.979 & 0.979 & 0.980 & 0.970 & 0.926 \\
Freundlich & $n$ & 0.80 & 1.46 & 0.95 & 0.97 & 0.97 & 0.90 \\
& $K_{\mathrm{f}}$ & 0.0048 & 0.0387 & 0.0014 & 0.2031 & 0.0673 & 0.0186 \\
& $R^{2}$ & 0.979 & 0.952 & 0.996 & 0.987 & 0.988 & 0.972 \\
Dubinin-Radu- & $K_{\text {ad }}$ & 0.0255 & 0.0195 & 0.0497 & 0.0030 & 0.0063 & 0.0139 \\
shkevich & $q_{\mathrm{s}}$ & 5.81 & 3.47 & 1.70 & 9.07 & 7.45 & 6.38 \\
& $E$ & 4.43 & 5.06 & 3.17 & 12.91 & 8.91 & 6.00 \\
& $R^{2}$ & 0.751 & 0.912 & 0.809 & 0.835 & 0.785 & 0.741 \\
\hline
\end{tabular}


Table 3 Comparison of surface modification technique on increasing adsorption capacity of ammonium

\begin{tabular}{|c|c|c|c|c|}
\hline Modification technique & Adsorbent & $q_{\mathrm{m}}(\mathrm{mgN} / \mathrm{g})$ & $\begin{array}{l}\text { Ratio of increasing } \\
\text { capacity }\left(q_{\mathrm{m}} / q_{\mathrm{m}}{ }^{*}\right)\end{array}$ & References \\
\hline \multirow[t]{26}{*}{ Pyrolysis } & S. rosthornii Seemen at $500{ }^{\circ} \mathrm{C}$ & $3.31 *$ & - & \multirow[t]{12}{*}{ Zeng et al. (2013) } \\
\hline & S. rosthornii Seemen at $600{ }^{\circ} \mathrm{C}$ & 7.43 & 2.24 & \\
\hline & S. rosthornii Seemen at $700^{\circ} \mathrm{C}$ & 6.61 & 2.00 & \\
\hline & T. dealbata at $500^{\circ} \mathrm{C}$ & $7.49 *$ & - & \\
\hline & T. dealbata at $600^{\circ} \mathrm{C}$ & 11.20 & 1.50 & \\
\hline & T. dealbata at $700^{\circ} \mathrm{C}$ & 17.60 & 2.35 & \\
\hline & V. zizanioides at $500{ }^{\circ} \mathrm{C}$ & $1.87^{*}$ & - & \\
\hline & V. zizanioides at $600^{\circ} \mathrm{C}$ & 3.12 & 1.67 & \\
\hline & V. zizanioides at $700{ }^{\circ} \mathrm{C}$ & 4.36 & 2.33 & \\
\hline & Phragmites sp. at $500^{\circ} \mathrm{C}$ & $2.21 *$ & - & \\
\hline & Phragmites sp. at $600^{\circ} \mathrm{C}$ & 2.43 & 1.10 & \\
\hline & Phragmites sp. at $700{ }^{\circ} \mathrm{C}$ & 5.43 & 2.46 & \\
\hline & Wheat straw at $400{ }^{\circ} \mathrm{C}$ & $7.33^{*}$ & - & \multirow[t]{12}{*}{ Gai et al. (2014) } \\
\hline & Wheat straw at $500{ }^{\circ} \mathrm{C}$ & 4.68 & 0.64 & \\
\hline & Wheat straw at $600^{\circ} \mathrm{C}$ & 3.16 & 0.43 & \\
\hline & Wheat straw at $700{ }^{\circ} \mathrm{C}$ & 2.64 & 0.36 & \\
\hline & Corn straw at $400{ }^{\circ} \mathrm{C}$ & $15.46^{*}$ & - & \\
\hline & Corn straw at $500^{\circ} \mathrm{C}$ & 12.05 & 0.78 & \\
\hline & Corn straw at $600^{\circ} \mathrm{C}$ & 8.62 & 0.56 & \\
\hline & Corn straw at $700{ }^{\circ} \mathrm{C}$ & 7.17 & 0.46 & \\
\hline & Peanut-shell at $400{ }^{\circ} \mathrm{C}$ & $10.52 *$ & - & \\
\hline & Peanut-shell at $500{ }^{\circ} \mathrm{C}$ & 9.92 & 0.94 & \\
\hline & Peanut-shell at $600{ }^{\circ} \mathrm{C}$ & 7.78 & 0.74 & \\
\hline & Peanut-shell at $700{ }^{\circ} \mathrm{C}$ & 4.01 & 0.38 & \\
\hline & RH & $13.95^{*}$ & - & \multirow[t]{2}{*}{ This study } \\
\hline & RHB at $500{ }^{\circ} \mathrm{C}$ & 44.05 & 3.16 & \\
\hline \multirow[t]{10}{*}{$\mathrm{NaOH}$ pre-treatment } & Peanut shells biochar & $200.43^{*}$ & - & \multirow[t]{6}{*}{ Liu et al. (2016) } \\
\hline & $\mathrm{NaOH}$ treated peanut shells biochar & 258.51 & 1.29 & \\
\hline & Corncobs biochar & $179.04 *$ & - & \\
\hline & $\mathrm{NaOH}$ treated corncobs biochar & 307.26 & 1.72 & \\
\hline & Cotton stalks biochar & $166.76^{*}$ & - & \\
\hline & $\mathrm{NaOH}$ treated cotton stalks biochar & 427.33 & 2.56 & \\
\hline & Basanites & $0.06^{*}$ & - & \multirow[t]{4}{*}{ Choi et al. (2014) } \\
\hline & $10 \% \mathrm{NaOH}$ treated basanites & 3.30 & 55.00 & \\
\hline & $20 \% \mathrm{NaOH}$ treated basanites & 5.38 & 89.67 & \\
\hline & $40 \% \mathrm{NaOH}$ treated basanites & 3.48 & 58.00 & \\
\hline \multirow[t]{2}{*}{ Sodium acetate-microwave } & Natural zeolite & $4.79 *$ & - & \multirow[t]{2}{*}{ Dong and Lin (2016) } \\
\hline & Sodium acetate and microwave treated zeolite & 6.56 & 1.37 & \\
\hline \multirow[t]{2}{*}{ Carboxylic acid modification } & Activated carbon & $1.75^{*}$ & - & \multirow[t]{2}{*}{ Halim et al. (2013) } \\
\hline & Carboxylic acid modified activated carbon & 7.52 & 4.30 & \\
\hline \multirow[t]{6}{*}{ Acid treatment } & Wheat straw biochar & $0.33^{*}$ & - & \multirow[t]{6}{*}{ Gai et al. (2014) } \\
\hline & $\mathrm{H}_{2} \mathrm{SO}_{4}$ washed wheat straw biochar & 0.27 & 0.82 & \\
\hline & Corn straw biochar & $0.92 *$ & - & \\
\hline & $\mathrm{H}_{2} \mathrm{SO}_{4}$ washed corn straw biochar & 0.45 & 0.49 & \\
\hline & Peanut-shell biochar & $0.54 *$ & - & \\
\hline & $\mathrm{H}_{2} \mathrm{SO}_{4}$ washed peanut-shell biochar & 0.43 & 0.80 & \\
\hline
\end{tabular}


Table 3 (continued)

\begin{tabular}{llclc}
\hline Modification technique & Adsorbent & $q_{\mathrm{m}}(\mathrm{mgN} / \mathrm{g})$ & $\begin{array}{l}\text { Ratio of increasing } \\
\text { capacity }\left(q_{\mathrm{m}} / q_{\mathrm{m}}{ }^{*}\right)\end{array}$ & References \\
\hline Surfactant modification & RH & $13.95^{*}$ & - & This study \\
& S-RH & 14.49 & 1.04 \\
& C-RH & 4.43 & 0.32 \\
& RHB & $44.05^{*}$ & - \\
& S-RHB & 14.73 & 0.33 \\
& C-RHB & 9.30 & 0.21 \\
\hline
\end{tabular}

${ }^{*}$ is unmodified material

The thermodynamics indicate the adsorption mechanism. If the value of $E=8-16 \mathrm{~kJ} / \mathrm{mol}$ then the adsorption process flows by chemical ion-exchange, and if $E<8 \mathrm{~kJ} / \mathrm{mol}$ the adsorption process is physical in nature; whereas if the value is more than $16 \mathrm{~kJ} / \mathrm{mol}$, the adsorption process is chemisorption in nature (Youssef et al. 2008). The adsorption free energy of ammonium on RHB $(12.91 \mathrm{~kJ} / \mathrm{mol})$ and S-RHB $(8.91 \mathrm{~kJ} / \mathrm{mol})$, therefore, indicates an ion exchange, while C-RHB tends to be physical sorption. This result is in agreement with the results of Clough et al. (2013) in their study of ammonium adsorption on biochar, and of Hou et al. (2016) whose results indicate that ion exchange was the main mechanism of ammonium adsorption on giant reed biochar.

Surface modification of rice husk using pyrolysis was a more effective method for increasing ammonium adsorption than using a surfactant modification technique, as the pyrolysis technique results in a greater negative charge value and surface area while the surfactant decreases surface area.

Comparing the adsorption capacity of RHB (44.05 mgN/g), the best ammonium adsorbent, with other studies, showed a lower result than that of Kizito et al. (2015) who examined the use of rice husk biochar to adsorb

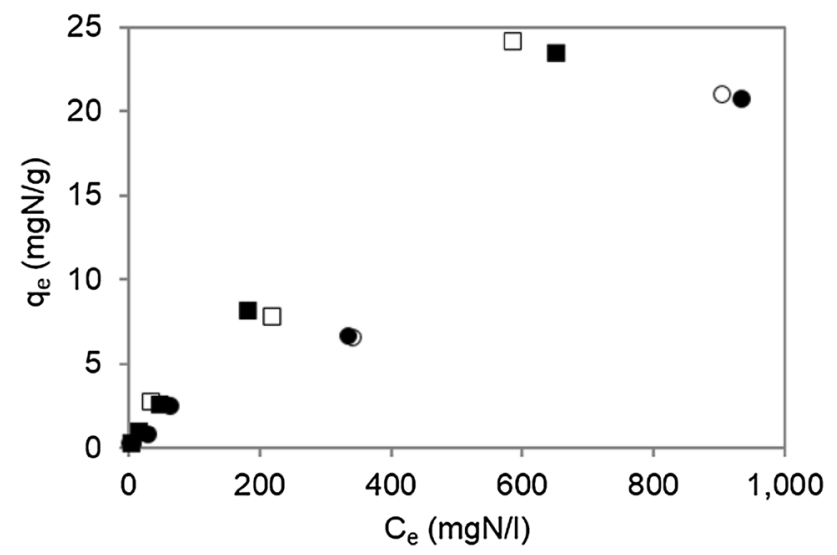

Fig. 3 Adsorption of nitrate $30-3000 \mathrm{mgN} / 1$ onto $\mathrm{RH}$ (open circle), RHB (filled circle), C-RH (open square), and C-RHB (filled square) at $25 \pm 1^{\circ} \mathrm{C}$, initial $\mathrm{pH}$ of $7.0 \pm 0.5$ ammonium at $1400 \mathrm{mgN} / 1\left(q_{\mathrm{m}}, 71.9 \mathrm{mgN} / \mathrm{g}\right)$. However, the results were in the range of other biochar studies (Table 3 ). There have been only limited studies on both unmodified and modified adsorbent. However, they are very useful for considering feasible modification techniques to increase the ammonium adsorption of an adsorbent. It has been shown that modifying the surface by pyrolysis could increase adsorption capacity of adsorbent material up to a maximum of 3 times; $\mathrm{NaOH}$ pre-treatment could increase adsorption by 55-90 times for mineral material, however, only around 2 times for biomass adsorbent; sodium acetate pre-treatment followed by microwave barely increases adsorption capacity (by 1.4 times); carboxylic acid modification leads to a small increase by 4 times, while $\mathrm{H}_{2} \mathrm{SO}_{4}$ acid treatment could decrease $q_{\mathrm{m}}$ value; and surfactant modification, as shown in this study, especially cationic could also decrease the ammonium adsorption capacity through decreasing the specific surface area. These show that pyrolysis gives comparable ammonium adsorption efficiency with a greater cost-effectiveness.

Table 4 Adsorption isotherm of nitrate $30-3000 \mathrm{mgN} / \mathrm{l}$ onto rice husk, rice husk biochar, and their modification with CTAB surfactant at $25 \pm 1{ }^{\circ} \mathrm{C}$, initial $\mathrm{pH}$ of $7.0 \pm 0.5$

\begin{tabular}{lllllc}
\hline Isotherm & Parameter & RH & C-RH & RHB & C-RHB \\
\hline Langmuir & $q_{\mathrm{m}}$ & 5.68 & 277.78 & 22.12 & 212.77 \\
& $K_{\mathrm{L}}$ & 0.0111 & 0.0002 & 0.0014 & 0.0003 \\
& $R^{2}$ & 0.989 & 0.998 & 0.996 & 1.000 \\
Freundlich & $n$ & 1.25 & 1.10 & 1.09 & 1.10 \\
& $K_{\mathrm{f}}$ & 0.079 & 0.073 & 0.038 & 0.070 \\
& $R^{2}$ & 0.987 & 0.985 & 0.987 & 0.998 \\
Dubinin- & $K_{\text {ad }}$ & 0.0060 & 0.0071 & 0.0109 & 0.0071 \\
Radushk- & & & & & \\
evich & & & & & \\
& $q_{\mathrm{s}}$ & 5.58 & 7.48 & 6.12 & 7.45 \\
& $E$ & 9.13 & 8.39 & 6.77 & 8.39 \\
& $R^{2}$ & 0.689 & 0.760 & 0.736 & 0.769 \\
\hline
\end{tabular}


Table 5 Comparison of surface modification technique on increasing adsorption capacity of nitrate

\begin{tabular}{|c|c|c|c|c|}
\hline Modification technique & Adsorbent & $q_{\mathrm{m}}(\mathrm{mgN} / \mathrm{g})$ & $\begin{array}{l}\text { Ratio of increas- } \\
\text { ing capacity } \\
\left(q_{\mathrm{m}} / q_{\mathrm{m}}{ }^{*}\right)\end{array}$ & References \\
\hline \multirow[t]{8}{*}{ Acid treatment } & Red mud & $26.03 *$ & - & \multirow[t]{2}{*}{ Cengeloglu et al. (2006) } \\
\hline & $\mathrm{HCl}$-treated red mud & 82.01 & 3.15 & \\
\hline & Wheat straw biochar & $0.021 *$ & - & \multirow[t]{6}{*}{ Gai et al. (2014) } \\
\hline & $\mathrm{H}_{2} \mathrm{SO}_{4}$ washed wheat straw biochar & 0.037 & 1.76 & \\
\hline & Corn straw biochar & $0.032 *$ & - & \\
\hline & $\mathrm{H}_{2} \mathrm{SO}_{4}$ washed corn straw biochar & 0.058 & 1.81 & \\
\hline & Peanut-shell biochar & $0.024 *$ & - & \\
\hline & $\mathrm{H}_{2} \mathrm{SO}_{4}$ washed peanut-shell biochar & 0.042 & 1.75 & \\
\hline \multirow[t]{2}{*}{ Acid thermoactivation } & Palm kernel shell & $13.58^{*}$ & - & \multirow[t]{2}{*}{ Adebayo et al. (2016) } \\
\hline & $\begin{array}{l}\text { Acid thermoactivation pulverized palm kernel } \\
\text { shell }\end{array}$ & 19.36 & 1.43 & \\
\hline \multirow[t]{11}{*}{ Surfactant modification } & Clinoptilolite-rich zeolite & $42,000.00 *$ & - & \multirow[t]{2}{*}{ Guan et al. (2010) } \\
\hline & CTAB modified clinoptilolite-rich zeolite & $336,000.00$ & 8.00 & \\
\hline & Kaolin-clay & $0.0002 *$ & - & \multirow[t]{3}{*}{ Aroke et al. (2014) } \\
\hline & Bilayer CTAB modified Kaolin-clay & 0.0278 & 123.00 & \\
\hline & Monolayer CTAB modified Kaolin-clay & 0.0061 & 27.00 & \\
\hline & Natural sepiolite & $-10.60 *$ & - & \multirow[t]{2}{*}{ Ozcan et al. (2005) } \\
\hline & $\begin{array}{l}\text { Dodecylethyldimethylammonium modified } \\
\text { sepiolite }\end{array}$ & 32.90 & $\sim 33.00$ & \\
\hline & RH & $5.68 *$ & - & \multirow[t]{4}{*}{ This study } \\
\hline & $\mathrm{C}-\mathrm{RH}$ & 277.78 & 48.90 & \\
\hline & RHB & $22.12^{*}$ & - & \\
\hline & C-RHB & 212.77 & 9.62 & \\
\hline \multirow[t]{2}{*}{ Impragnation } & Lignite granular activated carbon & $2.03 *$ & - & \multirow[t]{2}{*}{ Khan et al. (2011) } \\
\hline & $\begin{array}{l}\mathrm{ZnCl}_{2} \text { impregnated lignite granular activated } \\
\text { carbon }\end{array}$ & 2.30 & 1.14 & \\
\hline \multirow[t]{7}{*}{ Cross link with epichlorohydrin } & Chitosan & $12.71^{*}$ & - & \multirow[t]{3}{*}{ Jozwiak et al. (2014) } \\
\hline & Glutaraldehyde cross-linked chitosan & 34.99 & 2.75 & \\
\hline & Epichlorohydrin cross-linked chitosan & 38.47 & 3.03 & \\
\hline & Wheat residue & $0.28 *$ & - & \multirow[t]{2}{*}{ Wang et al. (2007) } \\
\hline & Epichlorohydrin cross-linked wheat residue & 29.12 & 104.00 & \\
\hline & Chitosan beads & $20.48^{*}$ & - & \multirow[t]{2}{*}{ Chatterjee et al. (2009) } \\
\hline & Epichlorohydrin cross-linked chitosan beads & 23.28 & 1.14 & \\
\hline
\end{tabular}

${ }^{*}$ is unmodified material

\section{Adsorption of nitrate}

As the surface charge did not affect the adsorption of the positively charged ammonium ion, only a positively charged surfactant, CTAB, was applied in the adsorption experiment of the negatively charge nitrate. As indicated, data of nitrate adsorption on rice husk, rice husk biochar and their modification with CTAB surfactant (Fig. 3) could be fitted well with Freundlich and Langmuir isotherms (Table 4). The $K_{\mathrm{f}}$ values indicated that RH was more efficient than RHB. This was similar to the results of Gai et al. (2014) that ammonium was greater adsorbed on biochar than nitrate. As the $q_{\mathrm{m}}$ values were $\mathrm{C}-\mathrm{RH} \sim \mathrm{C}-\mathrm{RHB}>\mathrm{RHB} \sim \mathrm{RH}$, this indicated that the modification with CTAB could increase the adsorption capacity for both raw rice husk and rice husk biochar. This result agrees with the results of Aroke et al. (2014) and Baker (2016) which showed that CTAB modified clay and zeolite could increase the adsorption capacity of nitrate, indicating also that the surface charge may play a major role in the adsorption of nitrate. The adsorption of nitrate on RHB is similar to RH; hence, surface area does not play a major role in nitrate adsorption unlike that of the adsorption of ammonia. Increasing the positive charge of the surface by using a positive charge surfactant could attract the negatively charged nitrate ion through electrostatic interaction. This is similar to the results of Xi et al. (2010) who showed 
that nitrate can be electrostatically attracted by a cationic surfactant modified organo-clay and surface area was not a key factor controlling adsorption.

Comparison of the $\mathrm{NO}_{3}-\mathrm{N}$ adsorption capacity of adsorbent in this study with other studies (Table 5) showed that $\mathrm{RH}$ is similar to the unmodified palm kernel shell (Adebayo et al. 2016), while the result of RHB is better than the wheat straw biochar, corn straw biochar and peanut-shell biochar (Gai et al. 2014). The modification of rice husk and rice husk biochar with CTAB could increase adsorption capacity by 10-49 times which is in the range of other surfactant modification studies (8-123 times). In addition, the adsorption capacity of C-RH $(277.78 \mathrm{mgN} / \mathrm{g})$ and of C-RHB ( $212.77 \mathrm{mgN} / \mathrm{g}$ ) were higher than the commercial resin Duolite A 171 (123.63 mg/g or $27.92 \mathrm{mgN} / \mathrm{g}$ ) (Sowmya and Meenakshi 2013). Surface modification using a surfactant shows the best increase in adsorption capacity compared with other modification techniques. This demonstrates an advantage of using household chemicals with simple modification technique.

\section{Conclusions}

A surfactant modification technique was not suitable for ammonium adsorption because the surfactant can clog the pores thereby lowering the specific surface area. Pyrolysis, however, was a more suitable technique to increase ammonium adsorption on rice husk by providing a more specific surface area and a more negatively charged surface. Pyrolysis also gave a satisfactory increase in ammonium adsorption capacity in biomass adsorbent with greater cost effectiveness as compared to other reviewed techniques: $\mathrm{NaOH}$ pretreatment, carboxylic acid modification, acid treatment. A cationic surfactant modification technique was suitable for nitrate adsorption because rice husk and rice husk biochar have neutral to negative charge; hence increasing the surface charge by a positive charge surfactant enhances nitrate attraction. In addition, surfactant modification seems to give the highest efficiency in improving nitrate adsorption capacity as compared to other reviewed techniques: acid treatment, acid with thermoactivation, surfactant modification, and cross-linking with epichlorohydrin. This study shows the alternative way of using rice husk to adsorb ammonium and nitrate with low cost which is advantage for wide practical application in the agricultural and industrial sectors. The further study on the desorption and plant uptake is interesting to examine in order to apply as nitrogen rich fertilizer and fertilizer retention.

Acknowledgements The authors would like to thank the Faculty of Science and Technology, Phranakhon Rajabhat University and
Chulalongkorn University for providing many facilities. This work was supported by the Phranakhon Rajabhat Research Fund under Grant No. $10.01 / 2558$.

\section{Compliance with ethical standards}

Conflict of interest The authors have no conflict of interest.

Open Access This article is distributed under the terms of the Creative Commons Attribution 4.0 International License (http://creativeco mmons.org/licenses/by/4.0/), which permits unrestricted use, distribution, and reproduction in any medium, provided you give appropriate credit to the original author(s) and the source, provide a link to the Creative Commons license, and indicate if changes were made.

\section{References}

Abdulrazzaq H, Jol H, Husni A, Abu-Bakr R (2014) Characterization and stabilisation of biochars obtained from empty fruit bunch, wood, and rice husk. Bioresources 9:2888-2898. https://doi. org/10.15376/biores.9.2.2888-2898

Adebayo OL, Adaramodu AA, Ajayi MG, Olasehinde FE, Oyetunde JG (2016) Purification of nitrate contaminated aqueous solution using modified and unmodified palmkernel shell. Int Lett Chem Phys Astron 71:11-18. https://doi.org/10.18052/www.scipress. com/ILCPA.71.11

Alvarez J, Lopez G, Amutio M, Bilbao J, Olazar M (2014) Upgrading the rice husk char obtained by flash pyrolysis for the production of amorphous silica and high quality activated carbon. Bioresour Technol 170:132-137. https://doi.org/10.1016/j.biort ech.2014.07.073

Angar Y, Djelali N-E, Kebbouche-Gana S (2017) Investigation of ammonium adsorption on Algerian natural bentonite. Environ Sci Pollut Res Int 24:11078-11089. https://doi.org/10.1007/s1135 6-016-6500-0

Aroke UO, El-nafaty UA, Osha OA (2014) Removal of oxyanion contaminants from wastewater by sorption onto HDTMA-Br surface modified organo-kaolinite. Int J Emerg Technol Adv Eng 4:475-484

Baker HM (2016) Studies of oxyanion removal from aqueous solution using zeolite and HDTMA-Br surface modified organozeolite. Am Chem Sci J 11:1-14. https://doi.org/10.9734/ ACSJ/2016/22053

Berthod A, Garcia-Alvarez-Coque C (2000) Micellar liquid chromatography. Marcel Dekker, New York

Cengeloglu Y, Tor A, Ersoz M, Arslan G (2006) Removal of nitrate from aqueous solution by using red mud. Sep Purif Technol 51:374-378. https://doi.org/10.1016/j.seppur.2006.02.020

Chatterjee S, Lee DS, Lee MW, Woo SH (2009) Nitrate removal from aqueous solutions by cross-linked chitosan beads conditioned with sodium bisulfate. J Hazard Mater 166:508-513. https://doi. org/10.1016/j.jhazmat.2008.11.045

Choi JW, Ryu JC, Kwon KS, Song MK, Lee S, Kim SB, Lee SH (2014) Adsorption of ammonium nitrogen and phosphate onto basanite and evaluation of toxicity. Water Air Soil Pollut 225:2059. https ://doi.org/10.1007/s11270-014-2059-x

Clough TJ, Condron LM, Kammann C, Müller C (2013) A review of biochar and soil nitrogen dynamics. Agronomy 3:275-293. https ://doi.org/10.3390/agronomy3020275

Dong Y, Lin H (2016) Ammonia nitrogen removal from aqueous solution using zeolite modified by microwave-sodium acetate. $\mathrm{J}$ 
Cent South Univ 23:1345-1352. https://doi.org/10.1007/s1177 1-016-3186-x

Dubinin MM, Radushkevich LV (1947) Equation of the characteristic curve of activated charcoal. In: Proceedings of the Academy of Sciences, Physical Chemistry Section USSR, vol 55, pp 331-333

Freundlish H (1906) Over the adsorption in solution. J Phys Chem 57:385-471

Gai X, Wang H, Liu J, Zhai L, Liu S, Ren T, Liu H (2014) Effects of feedstock and pyrolysis temperature on biochar adsorption of ammonium and nitrate. PLoS ONE 9:1-19. https://doi. org/10.1371/journal.pone.0113888

Guan H, Bestland E, Zhu C, Zhu H, Albertsdottir D, Hutson J, Simmons CT, Ginic-Markovic M, Tao X, Ellis AV (2010) Variation in performance of surfactant loading and resulting nitrate removal among four selected natural zeolites. J Hazard Mater 183:616621. https://doi.org/10.1016/j.jhazmat.2010.07.069

Halim AA, Latif MT, Ithnin A (2013) Ammonia removal from aqueous solution using organic acid modified activated carbon. World Appl Sci J 24:1-6

Hou J, Huang L, Yang Z, Zhao Y, Deng C, Chen Y, Li X (2016) Adsorption of ammonium on biochar prepared from giant reed. Environ Sci Pollut Res Int 23:19107-19115. https://doi. org/10.1007/s11356-016-7084-4

Jozwiak T, Filipkowska U, Szymczyk P, Mielcarek A (2014) Application of cross-linked chitosan for nitrate nitrogen (V) removal from aqueous solutions. Prog Chem Appl Chitin Deriv 19:41-52. https ://doi.org/10.15259/PCACD.19.05

Khan MA, Ahn YT, Kumar M, Lee W, Min B, Kim G, Cho DW, Park WB, Jeon BH (2011) Adsorption studies for the removal of nitrate using modified lignite granular activated carbon. Sep Sci Technol 46:2575-2584. https://doi.org/10.1080/01496395.2011.601782

Kizito S, Wu S, Kipkemoi Kirui W, Lei M, Lu Q, Bah H, Dong R (2015) Evaluation of slow pyrolyzed wood and rice husks biochar for adsorption of ammonium nitrogen from piggery manure anaerobic digestate slurry. Sci Total Environ 505:102-112. https ://doi.org/10.1016/j.scitotenv.2014.09.096

Langmuir I (1916) The constitution and fundamental properties of solids and liquids. Part I. Solids. J Am Chem Soc 38:2221-2295

Lippincott ER, Van Valkenburg A, Weir CE, Bunting EN (1958) Infrared studies on polymorphs of silicon dioxide and germanium dioxide. J Res Natl Bur Stand 61:61-70

Liu Z, Xue Y, Gao F, Cheng X, Yang K (2016) Removal of ammonium from aqueous solutions using alkali-modified biochars. Chem Speciat Bioavailab 28:26-32. https://doi.org/10.1080/09542 299.2016.1142833

Ma Z, Li Q, Yue Q, Gao B, Li W, Xu X, Zhong Q (2011) Adsorption removal of ammonium and phosphate from water by fertilizer controlled release agent prepared from wheat straw. Chem Eng J 171:1209-1217. https://doi.org/10.1016/j.cej.2011.05.027

Mahmoud MA (2015) Kinetics and thermodynamics of aluminum oxide nanopowder as adsorbent for Fe(III) from aqueous solution. Beni-Seuf Univ J Basic Appl Sci 4:142-149. https://doi. org/10.1016/j.bjbas.2015.05.008

Mathurasa L, Damrongsiri S (2017) Possibility of using surfactants to increase nitrogen adsorption on rice husk. Appl Environ Res 31:11-22

Mustafa G, Ali MA, Smith D, Schwinghamer T, Lamont JR, Ahmed N, Hussain S, Arshad M (2016) Guar, jantar, wheat straw, and rice hull composts as replacements for peat in muskmelon transplant production. Int J Recycl Org Waste Agric 5:323-332. https://doi. org/10.1007/s40093-016-0142-6
Ozcan A, Sahin M, Ozcan AS (2005) Adsorption of nitrate ions onto sepiolite and surfactant-modified sepiolite. Adsorpt Sci Technol 23:323-334. https://doi.org/10.1260/0263617054769987

Quan G, Pan X, Wang Z, Wu Q, Li G, Dian L, Chen B, Wu C (2015) Lactosaminated mesoporous silica nanoparticles for asialoglycoprotein receptor targeted anticancer drug delivery. J Nanobiotechnol 13:7. https://doi.org/10.1186/s12951-015-0068-6

Ramimoghadam D, Hussein MZB, Taufiq-Yap YH (2012) The effect of sodium dodecyl sulfate (SDS) and cetyltrimethylammonium bromide (CTAB) on the properties of $\mathrm{ZnO}$ synthesized by hydrothermal method. Int J Mol Sci 13:13275-13293. https://doi. org/10.3390/ijms131013275

Song Y, Subha B, Woo JH, Lim HJ, Senthilkumar P (2014) Surface modification of sediment with surfactant for capping material on contaminated coastal sediment. Water Air Soil Pollut 225:2067. https://doi.org/10.1007/s11270-014-2067-x

Sowmya A, Meenakshi S (2013) Removal of nitrate and phosphate anions from aqueous solutions using strong base anion exchange resin. Desalination Water Treat 51:7145-7156. https://doi. org/10.1080/19443994.2013.771286

Taffarel SR, Rubio J (2010) Adsorption of sodium dodecyl benzene sulfonate from aqueous solution using a modified natural zeolite with CTAB. Miner Eng 23:771-779. https://doi.org/10.1016/j. mineng.2010.05.018

Tian R, Seitz O, Li M, Hu W, Chabal YJ, Gao J (2010) Infrared characterization of interfacial $\mathrm{Si}-\mathrm{O}$ bond formation on silanized flat $\mathrm{SiO}_{2} / \mathrm{Si}$ surfaces. Langmuir 26:4563-4566. https://doi. org/10.1021/la904597c

Wang CC, Juang LC, Lee CK, Hsu TC, Lee JF, Chao HP (2004) Effects of exchanged surfactant cations on the pore structure and adsorption characteristics of montmorillonite. J Colloid Interface Sci 280:27-35. https://doi.org/10.1016/j.jcis.2004.07.009

Wang Y, Gao BY, Yue WW, Yue QY (2007) Adsorption kinetics of nitrate from aqueous solutions onto modified wheat residue. Colloids Surf A 308:1-5. https://doi.org/10.1016/j.colsu rfa.2007.05.014

Xi Y, Mallavarapu M, Naidu R (2010) Preparation, characterization of surfactants modified clay minerals and nitrate adsorption. Appl Clay Sci 48:92-96. https://doi.org/10.1016/j.clay.2009.11.047

Youssef AM, El-Khouly S, El-Nabarawy TH (2008) Removal of Pb(II) and $\mathrm{Cd}$ (II) from aqueous solution using activated carbons from pecan shells. Carbon Lett 9:8-13

Zeng Z, Zhang S, Li T, Zhao F, He Z, Zhao H, Yang X, Wang H, Zhao J, Rafiq MT (2013) Sorption of ammonium and phosphate from aqueous solution by biochar derived from phytoremediation plants. J Zhejiang Univ Sci B 14:1152-1161. https://doi. org/10.1631/jzus.B1300102

Zhou Z, Yuan J, Hu M (2015) Adsorption of ammonium from aqueous solutions on environmentally friendly barbecue bamboo charcoal: characteristics and kinetic and thermodynamic studies. Environ Prog Sustain Energy 34:655-662. https://doi.org/10.1002/ ep.12036

Publisher's Note Springer Nature remains neutral with regard to urisdictional claims in published maps and institutional affiliations. 